University of Nebraska - Lincoln

DigitalCommons@University of Nebraska - Lincoln

Nutrition and Health Sciences -- Faculty

Publications

Nutrition and Health Sciences, Department of

2003

\title{
Consumption of Omega-3 Fatty Acid-Enriched Eggs and Serum Lipids in Humans
}

\author{
Ji-Young Lee \\ University of Nebraska-Lincoln, ji-young.lee@uconn.edu \\ Nancy M. Lewis \\ University of Nebraska--Lincoln, nlewis2@unl.edu \\ Sheila Scheideler \\ University of Nebraska - Lincoln, spurdum2@unl.edu \\ Timothy P. Carr \\ University of Nebraska - Lincoln, tcarr2@unl.edu
}

Follow this and additional works at: https://digitalcommons.unl.edu/nutritionfacpub

Part of the Dietetics and Clinical Nutrition Commons

Lee, Ji-Young; Lewis, Nancy M.; Scheideler, Sheila; and Carr, Timothy P., "Consumption of Omega-3 Fatty Acid-Enriched Eggs and Serum Lipids in Humans" (2003). Nutrition and Health Sciences -- Faculty Publications. 2.

https://digitalcommons.unl.edu/nutritionfacpub/2

This Article is brought to you for free and open access by the Nutrition and Health Sciences, Department of at DigitalCommons@University of Nebraska - Lincoln. It has been accepted for inclusion in Nutrition and Health Sciences -- Faculty Publications by an authorized administrator of DigitalCommons@University of Nebraska Lincoln. 


\title{
Consumption of Omega-3 Fatty Acid-Enriched Eggs and Serum Lipids in Humans
}

\author{
Ji-Young Lee \\ Nancy M. Lewis \\ Sheila E. Scheideler \\ Timothy P. Carr
}

\begin{abstract}
This study examined the effectiveness of consuming omega-3 fatry acid-enriched eggs (Omega Eggs) in increasing rocal dietary omega-3 fatty acids. Also examined was the impact of Omega Egg consumption on serum lipids. Sixteen hypercholesterolemic men and women with baseline serum total cholesterol concentrations of 5.17-7.76 mmol/L (200-300 $\mathrm{mg} / \mathrm{dL})$ followed the National Cholesterol Education Progran Step I diet guidelines under the following conditions: (a) Step I diet without eggs, (b) Step I diet plus 12 regular eggs per week, and (c) Step I diet plus 12 Omega Eggs per weck. The study design was a repeated $3 \times 3$ Latin square so that each subject received each of the three
\end{abstract}

J-Young Lee, MS, is a doctoral student, luterdepattmental Nutrition Program, University of Nebraska-Lincoln.

Nancy M. Lewis, PhD, RD, is Associate Protessol of Nutrition, and Timothy P. Carr. PhD, is Associate Professor of Nutritional Biochemistry, Department of Nutritional Sciences and Dietetics, University of Nebraska-Lincoln.

Sheila E. Scheidcler, PhD. is Professor and Extension Pouluy Specialist, Department of Animal Science. University of Nebraska--Lincoln.

Address correspondence to: Timothy P. Carr, PhD, Nutritional Science and Dietetics, University of Nebraska, 376 Ruth Leverton Hall, Lineoln. NE 68583 (E-mail: tcarx $2 @$ unl.edu).

This work was supported by the U.S. Poultry and Egg Association, the North Dakota Oilseed Council, and the Nebraska Agriculture Research Division (Joumal Series No. 13018 )

Journal of Nutraceuticals, Fumetional \& Medical Foods, Vol 4(1) 2003

http://www.haworthpress.com/store/product.asp?sku=1133

(0) 2003 by The Haworth Press, Inc. All rights reserved.

$10.1300 / 1133 \times 04 n_{01} 02$ 
diet treatments. Consumption of Omega Eggs significandy increased omega-3 fatty acid intake ( $1.18 \mathrm{~g} /$ day) compared to consumption of regular eggs (0.71 g/day) or no eggs $(0.81 \mathrm{~g} / \mathrm{day})$. The Omega Egg treatment did not significantly alter serum cholesterol or triacylglycerol concentration when all 16 subjects were included in the analysis. However, three subjects showed a simificant increase in scrum total cholesterol concentation when consuming regular eggs relative to no eggs. When these "responders" consumed Omega Eggs, serum total cholesterol concentration did not increase, despite a 3-fold increase in cholesterol intake relative to no egg treatment. These data suggest that Omega Eggs (12/week) can be included in the National Cholesterol Education Program Step 1 diet without increased serum total cholesterol or triacylglycerol concentration. In this way, the nutritional benefits of eggs could be realized without the detrimental effects of increased cholesterol intake. /Aricle copies avalable for a fee from The Haworth Document Deliver: Service: 1-800-HAWORTH. E-mail address: <getinfo@haworthpresscom> Website: <htp://www.HoworthPresscoms 2003 by The Haworh Press, Inw All rights reserved.]

KEYWORDS. Omega 3 tatty acids, eggs, cholesterol, serum lipids, humans

\section{INTRODUCTION}

Consumption of fish rich in omega-3 PUFA in the United States is approximately one serving per week, while the dietary recommendation is one to two fish meals per week, ${ }^{2}$ Because the intake of lish is generally low, finding alternative sources of omega-3 PUFA is necessary to increase the omega-3 PUFA consumption in the United States and other countries.

Eggs have been studied as an alternative food source of omega-3 PUFA because they can be prodnced with an altered latty acid composition, depending on the hens" feed. ${ }^{3.4}$ It is reported that inclusion of various sources of omega 3 PUFA in hens' feed resulted in up $10220 \mathrm{mg}$ of omega-3 PUFA per egg yolk, equivalent to the amount of omega-3 PUFA in a $100 \mathrm{~g}$ serving of lean fish. ${ }^{5}$ Marshall et al. reported that onega 3 fatty acid-enriched eggs could be incorporated as an omega-3 PUFA source into the diet of health-conscious consumers.

Epidemiological studies in Greenland Eskimos led to the hypothesis that fish oil rich in omega-3 polyunsaturated fatty acids (PUFA) re- 
duces the risk of atherosclerosis..$^{7-9}$ Rescarch has shown that dietary omega-3 PUFA reduce atherosclerosis development, at least in part, by regulating serum cholesterol and triacylglycerol concentration. ${ }^{10}$

A few studies have been conducted to investigate the effects of omega- 3 fatty acid-enriched eggs on plasma lipid concentration. The consumption of four omega-3 fatty acid-enriched eggs per day resulted in lowered plasma triacylglycerol concentration and systolic and diastolic blood pressure, although plasma cholesterol concentration was not affected. " Ferrier et al. ${ }^{12}$ reported that incorporation of four $\alpha$-linolenic acid-enriched eggs per day to the typical diets of normolipidemics had no significant effect on serum cholesterol or triacylglycerol concentration. In contrast, Jiang and Sim ${ }^{13}$ showed that rats consuming omega-3 PUFA-enriched egg yolks reduce both plasma and liver cholesterol concentration. More research is needed to further delineate the role of dietary omega-3 fatty acid-enriched eggs in regulating plasma lipid concentrations. Therefore, the present study was conducted to determine the serum lipid response in hypercholesterolemic humans consuming eggs enriched in omega-3 fatty acids.

\section{MATERIALS AND METHODS}

\section{Subjects}

Subjects represent a subset of individuals who participated in a larger study previously published. ${ }^{14}$ The sixteen subjects selected for this study are those that successfully completed all three treatment periods described below. Volunteers were recruited through advertisements and flyers directed toward individuals whose serum total cholesterol levels were $5.17-7.76 \mathrm{mM}(200)-300 \mathrm{mg} / \mathrm{dL})$ and considered hypercholesterolemic. They were screened for general good health and willingness to comply with the procedures of the study. People who had health risks or factors affecting serum cholesterol levels were excluded. The exclusion criteria were: Pregnant or lactating women wishing to conceive over the period of study; tobacco users; alcohol users more than two drinks per day; regular users of prescription drugs for lowering cholesterol; regular blood donors and not willing to forgo this activity during the study; subjects allergic to eggs or egg products; subjects planning a weight-loss diet; subjects who experienced an addiction to drugs or alcohol within the last two years; subjects with high blood pressure; and subjects with a body mass index greater than $32.5 \mathrm{~kg} / \mathrm{m}^{2}$. 


\section{Diets and Experimental Design}

The dietary protocol was based on the National Cholesterol Education Program (NCEP) Step I diet which suggests 30\% of total calories from fat, $10 \%$ total calories from saturated fat, and less than $300 \mathrm{mg} /$ day of dictary cholesterol. ${ }^{15}$ Each subject was instructed to keep this diet regime throughout the study. Diet records were kept for three non-consecutive days during the last two weeks of each six-week treatment period and were analyzed using the Food Processor Plus computer program, Version 5.0 (ESHA Research, Salem, OR). Table I shows the diet compositions during each treatment period.

Three diet treatments were used in this study: (1) NCEP Step I diet and no egg, (2) NCEP Step I diet plus 12 regular eggs per week, and (3) NCEP Step I diet plus 12 omega-3 fatty acid-enriched eggs per week. The study design was a repeated $3 \times 3$ Latin square such that each subject received each of the three diet treatments. After a twoweek baseline period and six week-stabilization period for the Step I diet, diet treatments were randomly assigned to subjects in a manner consistent with the Latin square protocol. Each diet treatment was conducted for six weeks, with six-week washout periods between treatments to minimize possible carryover effects.

TABLE 1. Diet composition during treatment periods

\begin{tabular}{lccc}
\hline & & Treatment & \\
\cline { 2 - 4 } & No Egg & Regular Eg9 & Omega Egg \\
\hline Total Energy, J/fay & $7.47 \pm 0.45$ & $7.53 \pm 0.41$ & $7.43 \pm 0.40$ \\
Total Fat, \% energy & $25.2 \pm 1.5$ & $26.3 \pm 1.6$ & $25.6 \pm 1.6$ \\
SFA, \% energy & $7.69 \pm 0.61$ & $8.58 \pm 0.64$ & $7.85 \pm 0.47$ \\
MUFA, \% onergy & $8.67 \pm 0.60$ & $9.86 \pm 0.69$ & $9.40 \pm 0.65$ \\
PUFA, \% emergy & $5.68 \pm 0.53$ & $5.22 \pm 0.37$ & $5.56 \pm 0.44$ \\
Omega-3 FA, g/day & $0.81 \pm 0.14 \mathrm{a}$ & $0.71 \pm 0.08 \mathrm{a}$ & $1.18 \pm 0.12 \mathrm{~b}$ \\
Omega-6 FA. g/day & $7.38 \pm 0.92$ & $6.96 \pm 0.56$ & $7.41 \pm 0.70$ \\
Omega-6lomega-3 FA ratio & $10.5 \pm 0.9 \mathrm{~b}$ & $10.7 \pm 0.8 \mathrm{~b}$ & $7.0 \pm 0.8 \mathrm{a}$ \\
Cholesterol, mg/day & $157 \pm 17 \mathrm{a}$ & $475 \pm 29 \mathrm{~b}$ & $477 \pm 24 \mathrm{~b}$ \\
\hline
\end{tabular}

Vajues represont mean $-5 E M(n=16$ lor each troatment). Vaues within the same row having difterent superscripts are significantly different $(P<0.05)$, using one-way repeated measures ANOVA and Fisher's multiple comparison iest $S F A$, saturated fatty acids; MUFA, monounsaturated taty acids; PUFA, polyunsaturated fatty acids. 
The eggs used in this study were produced by the Department of Animal Science at the University of Nebraska-Lincoln. Regular eggs were produced by feeding hens a standard diel. Omega-3 fatty acid-enriched eggs (Omega Eggs) were produced utilizing a patented feeding formula and management program. 16

\section{Plasma and LDL Analysis}

Blood samples were taken after 12 hour fasting at the fourth week of each diet. Red blood cells were removed and an aliquot of serum was frozen at $-70^{\circ} \mathrm{C}$. Serum was analyzed within 24 hours for total cholesterol, high density lipoprotein (HDL) cholesterol, total triacylglycerol concentration according to NCEP guidelines, ${ }^{17}$ Serum low density lipoprotein (LDL) cholesterol concentration was calculated using the Friedewald equation. 18

Serum lipoprotcins were separated into fractions containing LDL and HDL by gel filtration chromatography using 4\% agarose (BioGel A $15 \mathrm{~m}, 200$ to 400 mesh, BioRad, Inc., Hercules. CA) as described by Rudel et a1. ${ }^{19}$ The composition of serum LDL was determined by quantifying the chemical components of LDL particles (i.e., triacylglycerol, cholesteryl ester, free cholesterol, phospholipid. and apolipoprotein B-100) as previously described. ${ }^{20}$ Briefly, serum LDL total cholesterol and triacylglycerol concentration was measured enzymatically using commercially available reagents (Boehringer Mannheim, Indianapolis, IN). Unesterified (free) cholesterol was also measured enzymatically (Wako Chemicals USA, Tnc., Richmond, VA). Esterified cholesterol was determined as the difference between total and free cholesterol. LDL phospholipids were estimated by measuring inorganic phosphorus using the method of Monison. ${ }^{21}$ Apolipoprotein B-100 was measured by immunoturbidimetric assay (Sigma Chemical Co., St. Louis, MO). LDL particle diameter was calculated according 10 the equation of Van Heek and Zilversmit. ${ }^{22}$

\section{Statistical Analyses}

Statistical comparison among treatment groups was determined by repeated measures one-way analysis of variance and Fisher's least significant difference test using SigmaStat (SPSS Science, Chicago, IL). Treatment differences were considered significant at the $P<0.05$ level. 


\section{RESULTS}

Diet compositions from the analysis of diet records are shown in Table 1. Dietary intake was similar during each treatment period with regard to daily total energy intake and percent of energy from total fat, saturated (SFA), monounsaturated (MUFA), and polyunsaturated (PUFA) fatty acids. The total daily intake of omega-3 fatty acids was significantly higher and the omega-6/omega-3 ratio was significantly lower during Omega Egg treatment. Consumption of both Regular Eggs and Omega Eggs resulted in higher cholesterol intake $(P<0.05)$.

Serum lipid concentrations are shown in Table 2. No significant treatment differences were detected in serum total, LDL, or HDL cholesterol or serum triacylglycerol. The chemical composition of serum LDL was also analyzed (Table 3 ). No significant treatment differences were detected in the chemical composition of LDL expressed as the number of lipid molecules per LDL particle. There was a tendency of LDL molecular weight to be higher in the Regular Egg treatment, although this trend did not reach statistical significance.

Among the 16 subjects there were three individuals whose serum total cholesterol concentration significantly increased during Regular Egg treatment compared to No Egg treatment (Table 4). Omega Egg treatment in these "cholesterol responders" prevented the increase in serum total cholesterol concentration, which was significantly lower than Regular Egg treatment and similar to No Egg treatment. A similar trend was observed in serum LDL cholesterol and triacylglycerol concentration, but these differences did not reach statistical significance.

TABLE 2. Serum lipid concentrations

\begin{tabular}{lccc}
\hline & & \multicolumn{1}{c}{ Treatment } \\
\cline { 2 - 4 } & No Egg & Regular Egg & Omega Egg \\
\hline Total Cholesterol & $5.94 \pm 0.20$ & mmol/L & \\
LDL Cholesterol & $3.84 \pm 0.19$ & $5.96 \pm 0.20$ & $6.05 \pm 0.20$ \\
HDL Cholesterol & $1.30 \pm 0.08$ & $3.80 \pm 0.21$ & $3.95 \pm 0.20$ \\
Triacylglycerol & $1.75 \pm 0.26$ & $1.37 \pm 0.10$ & $1.34 \pm 0.08$ \\
\hline
\end{tabular}

Values represent mean \pm SEM ( $n=16$ tor each treatment). No significant differences were detected among ireatment groups, using one way repealed measures ANOVA. 
TABLE 3. Serum LDL lipid composition, molecular weight, and particle diameter

\begin{tabular}{lccc}
\hline & \multicolumn{3}{c}{ Treatment } \\
\cline { 2 - 4 } & No Egg & Regular Egg & Omega Egg \\
\hline Cholesleryl Ester, molecules/particle & $2202 \pm 52$ & $2240 \pm 92$ & $2166 \pm 132$ \\
Triacylglycerol, molectles/particle & $736 \pm 53$ & $822 \pm 114$ & $698 \pm 47$ \\
Free Cholesterol, molecules/particle & $547 \pm 41$ & $575 \pm 44$ & $569 \pm 50$ \\
Phospholipid, molecules/particle & $1334 \pm 47$ & $1433 \pm 80$ & $1339 \pm 57$ \\
Molecular Weight, gipmole? & $3.84 \pm 0.07$ & $4.03 \pm 0.19$ & $3.80 \pm 0.17$ \\
LDL Diameler, angstroms & $225 \pm 5$ & $223 \pm 7$ & $216 \pm 5$ \\
\hline
\end{tabular}

Values represont mean \pm SEM $n=16$ for each trealment). No significant differences were detected among treatment groups, using one-way repeated measures ANOVA.

"LOL "rnolecular weight" rofers to the mass (grams) of LOL tipid and apolipoprolen B-100 constituenls per umole of 1..DL. particles. The following molecular weight values were used io calculale LOLL. MW: cholesteryl ester, 650; triacylglycerol, 885; free cholesterol 387; phospholipid, 775; and apolipoprotein B-100, 513,000.

TABLE 4. Serum lipid concentration in responders and nonresponders

\begin{tabular}{|c|c|c|c|c|c|c|}
\hline & \multicolumn{3}{|c|}{ Fesponders $(n=3)$} & \multicolumn{3}{|c|}{ Nonresponders $(n=13)$} \\
\hline & No Egg & Regular Egg & Omega Egg & No Egg & Regulä Ego & Omega $E g g$ \\
\hline & \multicolumn{6}{|c|}{$\mathrm{mmol} / \mathrm{L}$} \\
\hline Total Cholesterol & $5.84 \pm 0.69$ & $6.35 \pm 0.56^{\circ}$ & $5.97 \pm 0.63$ & $5.96 \pm 0.20$ & $5.87 \pm 0.21$ & $6.06 \pm 0.22$ \\
\hline LDL Cholesterol & $4.04+0.65$ & $4.26 \pm 0.48$ & $4.03+0.59$ & $3.79 \div 0.20$ & $3.70 \pm 0.24$ & $3.93 \pm 0.22$ \\
\hline HDL Cholesterol & $1.15+0.17$ & $1.24 \div 0.24$ & $1.29+0.15$ & $-1.33+0.09$ & $1.40+0.11$ & $1.35 \div 0.10$ \\
\hline Triacylglycerol & $1.43 \pm 0.38$ & $1.87 \pm 0.58$ & $1.44 \pm 0.45$ & $1.83 \pm 0.31$ & $1.69 \pm 0.30$ & $1.72 \div 0.31$ \\
\hline
\end{tabular}

Vaiues represent mean \pm SEM, Values within the same row having different superschipts are significantly difterent $(P<0.05)$, using one-way repeated measures ANOVA and Fisher's multiple comparison test.

\section{DISCUSSION}

This study was conducted to determine whether total omega-3 fatty acid intake could be increased in a habitual diet by consuming eggs enriched in omega-3 fatty acids (Omega Eggs). Also examined was the impact of consuming Omega Eggs on senum lipid concentration and LDL chemical composition. The results show that addition of Omega Eggs to the subjects' diets significantly increased total omega-3 fatty acid intake compared to No Egg and Regular Egg treatment. Although omega- 3 fatty acid intake increased about $400-500 \mathrm{mg} /$ day by consuming Omega Eggs, this dietary level had limited impact on serum lipids. 
Dietary linolenic acid (C18:3) can be converted to docosahexaenoic acid (C22:6) in the body, which is physiologically essential for normal function of nervous tissue membranes. However, the enzymes involved in this conversion are common to the pathway for the elongation and desaturation of linoleic acid (C18:2), and competition with omega-6 fatty acids will reduce the amount of $\mathrm{C} 18: 3$ converted to $\mathrm{C} 22: 6 .{ }^{23}$ Hence, dietary recommendations in Canada include an omega- 6 to omega-3 fatty acid ratio as low as $4: 1$ and not higher than $10: 1.24$ The omega- 6 to omega-3 fatty acid ratio in the No Egg and Regular Egg treatments were slightly higher than 10:1, which is a similar ratio reported by Raper et al 25 The omega- 6 to omega- 3 fatty acid ratio in the Omega Egg treatment was 7:1. This is an important consideration because both long-chain omega- 6 and omega- 3 fatty acids are used for synthesis of specific eicosanoids as well as serving a functional role in cellular membrane phospholipids.

Serum lipid concentrations were relatively unchanged by the addition of Regular Eggs or Omega Eggs to the diet (Table 2). In a similar study, Ferrier et al. ${ }^{12}$ also found no significant differences in plasma total or HDL cholesterol concentration in subjects consuming either four regular eggs or four omega-3 fatty acid-enriched eggs per day. In contrast, Oh et al. " reported that plasma total cholesterol concentration was significantly increased by consumption of regular eggs but unchanged in subjects fed four omega- 3 fatty acid-enriched eggs per day. Because of the wide variation in serum lipid response seen in the human population, it is possible that our sample size was too small to detect a cholesterol-lowering effect of omega-3 fatty acids at the levels consumed in our study. There were, however, three subjects whose serum total cholesterol concentration significantly increased during the Regular Egg treatment (Table 4). The proportion of "cholesterol responders" to dietary cholesterol in the present study $(19 \%)$ is consistent with the proportion found in the general population, which is estimated to be $15-20 \%,{ }^{26}$ There is now substantial evidence that while dietary cholesterol has little effect on serum cholesterol concentration in the general population, 27,28 there exists a high degree of variability in the response of individuals to dietary cholesterol. ${ }^{26}$ This conclusion is supported by the present data, although one should be cautious about overemphasizing the results of only three subjects.

Dietary omega-3 fatty acids have been reported to lower serum triacylglycerol concentrations. ${ }^{29-32}$ Although Omega Egg consumption significantly increased omega-3 fatty acid intake, no significant differences in serum triacylglycerol concentration was observed among treat- 
ments. In the three responders, Omega Egg consumption appeared to prevent the tendency for serum triacylglycerol concentration to increase when Regular Eggs were consumed. In a previous study, a fish oil diet containing $24 \mathrm{~g} /$ day of omega-3 fatty acids significantly lowered plasma triacylglycerol concentration. ${ }^{33}$ Lower doses of fish oil (2-8 g/day of omega-3 fatty acids) were also effective at reducing plasma triacylglycerol concentration. ${ }^{34,35}$ In the present study, the mean omega-3 fatty acid intake was $1.18 \mathrm{~g} /$ day during Omega Egg treatment. While this level of intake was significantly higher than No Egg or Regular Egg treatment, it was apparently too low to elicit a significant change in serum triacylglycerol concentration.

Another objective of this study was to measure the compositional changes in serum LDL particles as influenced by dietary omega-3 fatty acids. No significant compositional changes were detected in the major lipid components of LDL. Our results are consistent with Sørensen et al. ${ }^{36}$ who reported no effect of omega-3 fatty acid consumption $(\sim 1$ g/day) on LDL chemical composition or size. Greater dietary intake of omega-3 fatty acids may be required to elicit changes in LDL composition or to enrich LDL lipids with omega-3 fatty acids.

\section{CONCLUSIONS}

The inclusion of Omega Eggs (12/week) to the NCEP Step I diet significantly increased the omega- 3 fatty acid content of the diet approximately 400-500 $\mathrm{mg} / \mathrm{day}$. Omega Egg consumption also appeared to prevent an increase in serum total cholesterol concentration in three individuals who appeared to be "responders" to dietary cholesterol. These data suggest a therapeutic use of Omega Eggs in managing senum cholesterol in individuals who are sensitive to dietary cholesterol. In this way, the nutritional benefits of eggs could be realized without the detrimental effects of increased cholesterol intake.

\section{REFERENCES}

1. United States Department of Agriculture. Food consumption, prices, and expendime: 1970-1990. Statistical Bulletin 840, Washington, DC. Economic Research Service, 1992

2. Kromhout D. Dietary fats: Long-term implications tor headth. Nutr Re1, 50:49-53, 1992. 
3. Naber EC. The effect of nutrition on the composition of eggs. Poultry Sct, $58.518 .528,1979$.

4. Van Elswyk ME. Designer foods: manipulating the fatty acid composition of meat and eggs for the health conscious consumer. Nur Today, March/April:21-27, 1993.

5. Hargis PS and Van Elswyk ME. Manipulating the fatly acid composition of poultry meat and eggs for the health conscious consumer. World's Poultry Sci $J$, $49: 251-264,1993$.

6. Marshall AC, Kubena KS, Hinton KR, Hargis PS and Van Elswyk ME n-3 fatty acid entiched table eggs: A survey of consumer acceptability. Pouftry Sci, 73:1334-1340. 1994.

7. Bang HO, Dyerberg J and Nielsen AB. Plasma lipid and lipoprotein pattem in Greenlandic west-coast Eskimos. Lancet, 1:1143-1145, 1971.

8. Bang HO, Dyerberg J and Home N. The composition of lood consumed by Grecnland Eskimos. Acta Med Scand, 200:69-73, 1976.

9. Dyerberg $I$, Bang HD and Hjome N. Fatty acid composition of the plasma lipid in Greenland Eskimos. An J Clin Nutr. 28:958-966, 1975.

10. Harris WS. Fish oils and plasma lipid and lipoprotein metabolism in humans: A critical review. $J$ Lipid Res, 30:785-807, 1989.

11. Oh SY. Ryue Y, Hsieh C and Bel DE. Eggs enriched in onega 3 fatty acids and alteations in lipid concentations in plasma and lipoproteins and in blood pressure. Am J Clin Nutr, 54:689-695, 1991.

12. Ferrier LK, Caston LJ, Leeson S, Squires J, Weaver BJ and Holub BJ $\alpha$-Linolenic acid-and docosahexaenoic acid-enriched eggs from hens fed flaxseed: Influence on blood lipids and platelet phospholipid fatty acids in humans. An I Clin Nutr, 62:81-86, 1995 .

13. Jiang $Z$ and Sim JS. Effects of dietary $n-3$ fatty acid-enrichen chicken eggs on plasma and tissue cholesterol and fatty acid composition of rats. Lipidis, 27:279-284, 1992.

14. Lewis ML, Schalch K and Scheideler SE. Serum lipid response to $\mathrm{n}-3$ fatty acid enriched eggs in persons with hypercholesterolemia. I Am Diot Assot, 100:365-367, 2000 .

15. National Cholesterol Education Progam. Population strategies for blood chow lesterol reduction. NIH Pub. No 90-3046. Wastington, DC. DHHS (PHS), National Institutes of Healh. National Heart, Lung, and Blood Institute, 1990.

16. Scheideler SE. Feed to produce omega-3 faty ucid enriched eggs and method for producing such eggs. U.S. Patent $75,897,890$; April 27, 1999.

17. National Cholesterol Education Program. Cument status of blood cholesterol measurement in clinical laboratories in the United States: A report from the Laboratory Standardization Panel of the National Cholesterol Education Program. Clin Chem, 34:193-201, 1988.

18. Friedewald WT, Levy RI and Fredrickson DS. Estimation of the concentration of low-densicy lipoprotein cholesterol in plasma. without use of preparative ultracentrifuge. Clin Chem, 18:499-502, 1972.

19. Rudel LL, Marzetta CA and Johnson FL. Separation and analysis of lipoproteins by gel fituration. Meth Enzymol, 129:45-57, 1986. 
20. Canr TP. Cai G, Lee J-Y and Schneider CL. Cholesteryl ester enrichment of plasma low-density lipoproteins in hamsters fed cereal-based dicts contaning cholesterol. Proc Soc Exp Biol Med, 223:96-101, 2000.

21. Morrison WR. A fast, simple and reliable method for the microdetemination of phosphorns in biological materials. Anal Biochem, 7:218-224, 1964.

22. Van Heek $M$ and Zilversmit DB. Mechanisms of hypertriglyceridemia in the coconut oil/cholesterol-fed rabbit. Increased secretion and decreased catabolism of very low density lipoprotein. Arterioscler Thromb, 11:918-927, 1991.

23. Chan JK, McDonald BE, Gerrard JM, Bruce VM, Weaver BJ and Holub BJ. Effect of dietary $\alpha$-linolenic acid and its ratio to linoleic acid on platelet and plasma faty acids and thrombogenesis. Lipids, 28:811-817, 1993.

24. Health and Wolfare Canada. Nutrition Recommendations: Report of the Scien. tific Review Committee. Ottawa, Minister of Supply and Services Canada, 1990.

25. Raper NR, Cronin FJ and Exler J. Omega-3 tatty acid content of the US food supply. J Am Coll Nutr, 11:304-308, 1992.

26. McNamara DJ. Cholesterol intake and plasma cholesterol: An update. I Am Coll Nutr. 16:530-534, 1997.

27. Clarke R, Frost C, Collins R, Appleby P and Peto R. Dietary lipids and blood cholesterol: quanticative mela-analys is of metabolic ward studies. BMJ, 314:112-117. 1997.

28. Howell WH, McNamara DJ, Tosca MA, Smith BT and Gaines JA. Plasma lipid and lipoprotein responses to dietary fat and cholesterol: A meta-analysis. Am 3 Clin Nutr. 65:1747-1764.1997.

29. Al-Shurbaji A, Larsson-Backstrom C, Berglund L, Eggertsen $\mathrm{G}$ and Bjorkhem 1. Effect of $n-3$ fatty acids on the key enzymes involved in cholesterol and triglyceride turnover in rat liver. Lipids, 26:385-389, 1991.

30. Harris WS, Connor WE, IJingworth DR and Foster DM. The mechanism of the hypotriglyceridemic effect of dictary omega-3 fatty acids in man. Clin Res, 32:102-107, 1984.

31. Phillipson BE, Rothrock DW, Connor WE, Harris WS and nlingworth DR. Reducion of plasma lipids, lipoproteins, and apoproteins by dietary fish oils in patients with hypertriglyceridemia. N Engl J Med, 312:1210-1216, 1985.

32. Wong $S$ and Nestel PJ. Eicosapentaenoic acid inhibits the secretion of triacyl. glycerol and apoprotein B and the binding of LDL in HepG2 cells. Atherosclerosis, $64: 139-146,1987$.

33. Illingworth DR, Harris WS and Connor WE. Inhibition of low density lipoprotein synthesis by dietary onega-3 fatty acids in man. Arteriosclerosis, 4:270-275. 1984.

34. Brongrest-Schoute HC, VanGent CM, Luten JB and Ruiter A. The effect of various intakes of omega-3 fatty acids on the blood lipid composition in healthy human subjects. Am J Clin Nutr, 34:1752-1757. 1981.

35. Sanders $\mathrm{TAB}$ and Roshana $F$. The influence of different omega-3 polyunsaturated fatty acids on blood lipids an platelet function in healthy voluntecrs. Clin Sci, $64,91-99,1983$

36. Sorensen NS, Marckmann P. Hoy CE, van Duyvenvoorde $W$ and Princen TMG. Effect of fish oil enriched margarine on plasma lipids, low-density lipoprotein particle composition, size, and susceptibility to oxidation. Am J Clin Nur, 68:235-241, 1998. 